\title{
EFFECT OF SOIL WATER CHARACTERISTIC CURVE (SWCC) SHAPE OF EXPANSIVE SOILS
}

\author{
D.Abdelmoneim ${ }^{1}$, , S. A.Akl ${ }^{1}$, H.H.Mamlouk ${ }^{1}$ and M.El-Taher ${ }^{2}$ \\ ${ }^{1}$ Cairo University, Faculty of Engineering, Public Works Department, Egypt \\ ${ }^{2}$ Suez canal University, Egypt
}

\begin{abstract}
The swelling pressure induced by expansive soils is considered a valuable parameter for the design of structures resting on these soils. It must be estimated in order to prevent damage to these structures and to design safe shallow foundations. In the recent research studies, the swelling pressure of expansive soil was predicted using the soil water characteristics curve SWCC. The present work investigates the interplay of the SWCC with the swelling pressure of expansive soil. The ABAQUS software was implemented in order to perform a coupled analysis of the expansive soil behavior. Published properties of the Regina expansive soil was used in order to validate the present numerical model. The validated numerical model showed good agreement with the published data of the Regina clay. The effect of the SWCC shape on the swelling pressure was thoroughly studied. The present results show a significant effect of the SWCC shape on the swelling pressure of the expansive soils.
\end{abstract}

\section{KEYWORDS: Expansive Soil; Finite Element; Soil Water Characteristic Curve; Swelling Pressure.}

\section{INTRODUCTION}

Swelling pressure of an expansive soil is defined as the pressure required to hold the soil or to restore it to its initial volume when water is added to the soil [1]. It is a very valuable parameter for the design of structures resting on swelling soils in order to prevent their damage[2].Due to this reason, extensive studies were conducted to evaluate the swelling pressure. The methods which are used to obtain the swelling pressure can be divided into three categories; empirical methods, soil suction methods, and oedometer methods [3]. The oedometer apparatus is widely used for testing the swelling soil and predicting its heave. The free swell oedometer test, constant volume oedometer test, and loaded swell oedometer test are considered the most commonly used methods. The loaded swell method has an important advantage over the other methods. As the loading-wetting procedure in this method follows the same sequence as in the field [1].

The soil water characteristic curve (SWCC) for a soil represents the relationship between the water content and the suction pressure of this soil [4]. It defines the ability of the soil to store and release water [5]. The water content can be represented using volumetric water content $(\theta)$, gravimetric water content $(\mathrm{w})$, or degree of saturation $(\mathrm{S})$. The suction may either be a matric suction or a total suction (matric plus osmotic suction). The matric suction is also known as the capillary pressure of the soil $\left(u_{a}-u_{w}\right)$, where $u_{a}$ is the pore-air pressure and $u_{w}$ is the pore water pressure. Generally, the matric suction and the total suction can be assumed to be equivalent [4]. The soil water characteristic curve is a valuable tool for the prediction of unsaturated soil property functions such as the permeability function. Determination of the SWCC in laboratory is a difficult and a time consuming task [5].For these reasons, a number of equations were suggested to obtain the SWCC. Fredlund and Xing [4] proposed an equation to fit the laboratory 
data over the entire soil suction range. It was found that this equation is the best equation to represent the SWCC [6].

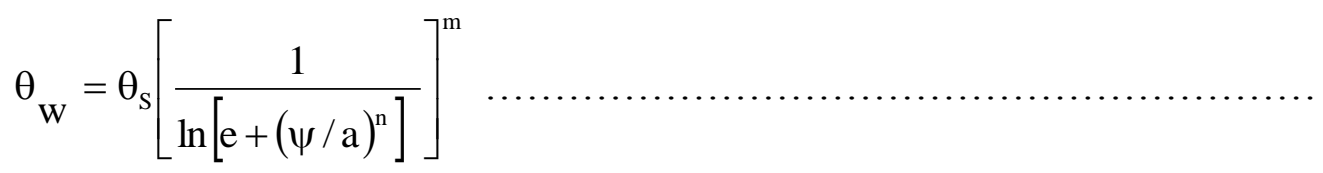

where $\psi$ is the soil suction $(\mathrm{kPa})$, e is the natural logarithm (base 2.71828), $\theta_{\mathrm{s}}$ is the volumetric water content at saturation, ais a soil parameter that is related to the air-entry value of the soil $(\mathrm{kPa})$, nis a soil parameter that controls the slope at the inflection point in the soil-water characteristic curve, and $\mathrm{m}$ is a soil parameter that is related to the residual water content of the soil.

During the last two decades, several models were suggested for predicting the unsaturated soil properties using the Soil Water Characteristics Curve (SWCC) as a tool. These models are considered simple valuable approaches for geotechnical engineers to implement mechanics of unsaturated soils in practice [3]. In the recent research studies, the same concept was used for predicting the swelling pressure of expansive soils. Tu and Vanapalli [3] presented a model to predict the swelling pressure $\left(\mathrm{p}_{\mathrm{s}}\right)$ for sand-bentonite mixtures using the SWCC as a tool with a fitting parameter "a"

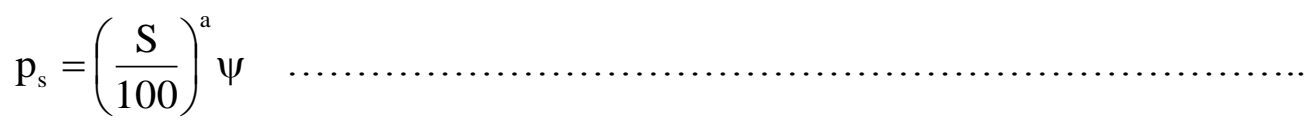

Where $\mathrm{S}$ is the degree of saturation and $\psi$ is the soil suction. The results suggested a strong relationship between the fitting parameter "a" and the dry density. This model was used to predict the swelling pressure of sand-bentonite mixtures only. Tu and Vanapalli [3] proposed semi-empirical models to predict the variation of the swelling pressure of both compacted and natural expansive soils using the SWCC as a tool. An empirical relationship is also suggested for estimating the swelling index from plasticity index values in order to reduce the need for conducting oedometer tests[3].

Many authors have numerically investigated the behavior of expansive soils [7-11]. The present work introduces the interplay of the SWCC with the swelling pressure of expansive soils. The ABAQUS software was implemented in order to perform a coupled analysis of the expansive soil behavior. The Regina expansive clay was used in the present work. The effect of the SWCC shape on the swelling pressure was investigated. The SWCC shape was varied by changing the values of the three fitting parameters (a, $m$, and $n$ ) in Fredlund and Xing equation [4].

\section{DESCRIPTION OF REGINA CLAY BEHAVIOR 3.1. Mechanical Properties of Regina Clay.}

Regina clay was selected for use in the present numerical analysis. Its properties were investigated by several researchers (e.g., Shuai [1]) and widely reported in the literature. Shuai [1] measured the test data of the Regina clay along the wetting path under the confined condition and initial suction of $575 \mathrm{kPa}$. These conditions were also considered in the present study. Table 1 presents the index properties and mineralogical composition for the investigated Regina clay soil. 
Table 1Index properties of the Regina clay soil [1]

\begin{tabular}{|c|c|}
\hline Soil: & Regina clay \\
\hline Location: & Regina, Sask., Canada \\
\hline Atterberg limits: & $\mathrm{LL}=69.9 \%, \mathrm{PL}=31.9 \%, \mathrm{PI}=38.0 \%$ \\
\hline $\begin{array}{l}\text { Grain size distribution (based on ASTM } \\
\text { D422,1988): }\end{array}$ & Sand: $2.2 \%$, Silt: $32.9 \%$, clay: 64.9 \\
\hline Unified Soil Classification System: & $\mathrm{CH}$, Inorganic clay of high plasticit \\
\hline Standard compaction: & $\begin{array}{l}\text { Maximum dry density: } 14.01 \mathrm{kN} / \mathrm{m}^{3} \\
\text { Optimum water content: } 28.5 \%\end{array}$ \\
\hline Mineralogical composition: & Montmorillonite: $20 \%$, Illite: $42 \%$, \\
\hline \multicolumn{2}{|c|}{$\begin{array}{l}\text { The soil mechanical behavior was modeled with a non-linear porous elastic mod } \\
\text { elastic portion of the constitutive model and Drucker- Prager plasticity model to } \\
\text { behavior in the plastic region. The porous bulk modulus } \kappa \text { is calculated by equa } \\
\text { Drucker-Prager parameters were calculated from the Mohr-Coulomb parameter } \\
\text { (4) and (5) [13]. The yield function of the hardening model is calculated from ec } \\
2 \text { introduces the mechanical properties of Regina expansive clay while Figure } \\
\text { function of the hardening model. }\end{array}$} \\
\hline \multicolumn{2}{|c|}{$\begin{array}{l}\text { Where Cs is the swell index from the conventional 1-D consolidation test. } \\
\qquad \sin \phi^{\prime}\end{array}$} \\
\hline \multicolumn{2}{|l|}{$d=\frac{18 c^{\prime} \cos \phi^{\prime}}{3-\sin \phi^{\prime}} \ldots .}$. \\
\hline$\varepsilon_{v o l}^{p l}=\frac{\lambda-\kappa}{1+e_{0}} \ln \frac{p^{\prime}}{p_{0}^{\prime}}=\frac{C_{c}-C_{s}}{2.3\left(1+e_{0}\right)} \ln \frac{p^{\prime}}{p_{0}^{\prime}}$ & \\
\hline
\end{tabular}

Table 2Mechanical properties of Regina expansive clay [1,14]

\begin{tabular}{ll}
\hline \multicolumn{1}{c}{ Soil Properties } & Values \\
\hline Specific gravity, $G_{s}$ & 2.83 \\
\hline Swelling index,$c_{s}$ & 0.0645 \\
\hline Soil unit weight , $\gamma_{b}$ & $17.27 \mathrm{KN} / \mathrm{m}^{3}$ \\
\hline Effective frictional angle,$\varphi^{\prime}$ & 20 degree \\
\hline Effective cohesion,$c^{\prime}$ & $0 \mathrm{kPa}$ \\
\hline Porous bulk modulus,$\kappa$ & 0.028 \\
\hline Poisson's ratio,$v$ & 0.4 \\
\hline Flow stress ratio, $\mathrm{K}$ & 1 \\
\hline Compression index,$C_{c}$ & 0.276 \\
\hline Log hardening constant,$\lambda$ & 0.12 \\
\hline
\end{tabular}




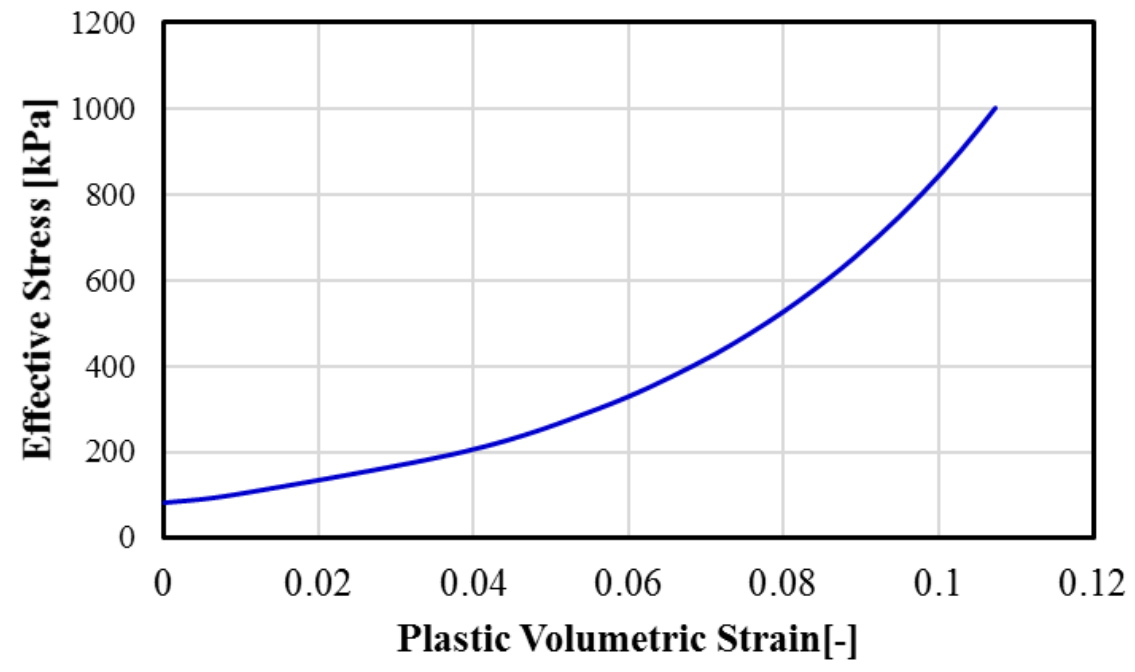

Figure 1 The yield function of the Regina clay

\subsection{Soil Suction Properties of Regina Clay.}

In the present work, the soil-water characteristic curve of Regina clay was represented using the Fredlund and Xing equation (1994). Equation (1) was implemented with $\theta \mathrm{s}=49.3 \%, \mathrm{a}=300 \mathrm{kPa}$, $\mathrm{n}=0.6$, and $\mathrm{m}=0.7$ (Hung 2004)[15] to best fit the measured volumetric water content data of Regina clay and get a continuous relation between the volumetric water content and the soil suction.

The void ratio-matric suction relationship for Regina clay soil was fitted using the Vu Hung equation [16] with four fitting parameters A, B, C, and D:

$\mathrm{e}=\mathrm{A}+\mathrm{B} \log \left(\frac{1+\mathrm{C} \cdot \mathrm{U}}{1+\mathrm{D} \cdot \mathrm{U}}\right)$

Where e is the void ratio, and $U$ is the matric suction. The values of the fitting parameters for Regina expansive clay are shown in Table 3. Variation of the void ratio with the matric suction for the Regina clay is shown in Figure 2.

Table 3Fitting parameters of the void ratio-matric suction forRegina clay [16]

\begin{tabular}{|c|c|c|c|}
\hline $\mathrm{A}$ & $\mathrm{B}$ & $\mathrm{C}$ & $\mathrm{D}$ \\
\hline 1.1078 & -0.0624 & 0.2936 & $4.80 \mathrm{E}-04$ \\
\hline
\end{tabular}

The degree of saturation(S) for Regina clay was obtained from the volumetric water content $\theta_{\mathrm{w}}$ and the void ratio:

$\mathrm{S}=\frac{\theta_{\mathrm{w}}(1+\mathrm{e})}{\mathrm{e}}$.

Figure 3 introduces the degree of saturation-matric suction relationship for the Regina soil. Figure 4 presents the relationship between the void ratio and the saturated coefficient of permeability for Regina clay while Figure 5 introduces the coefficient of permeability as a function of the matric suction. 


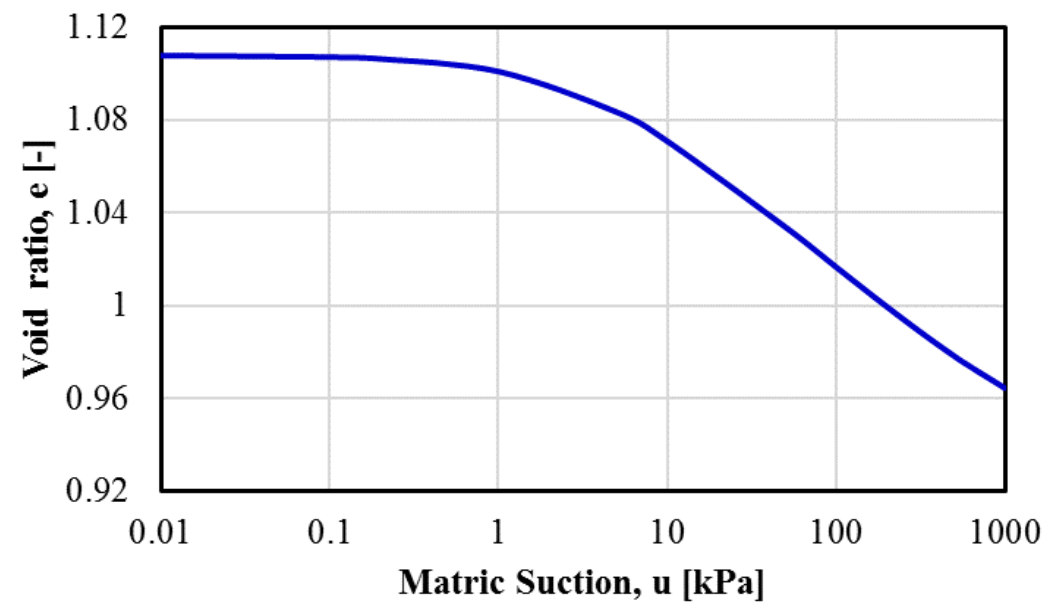

Figure 2 Best-fit void ratio versus matric suction curve for Regina clay

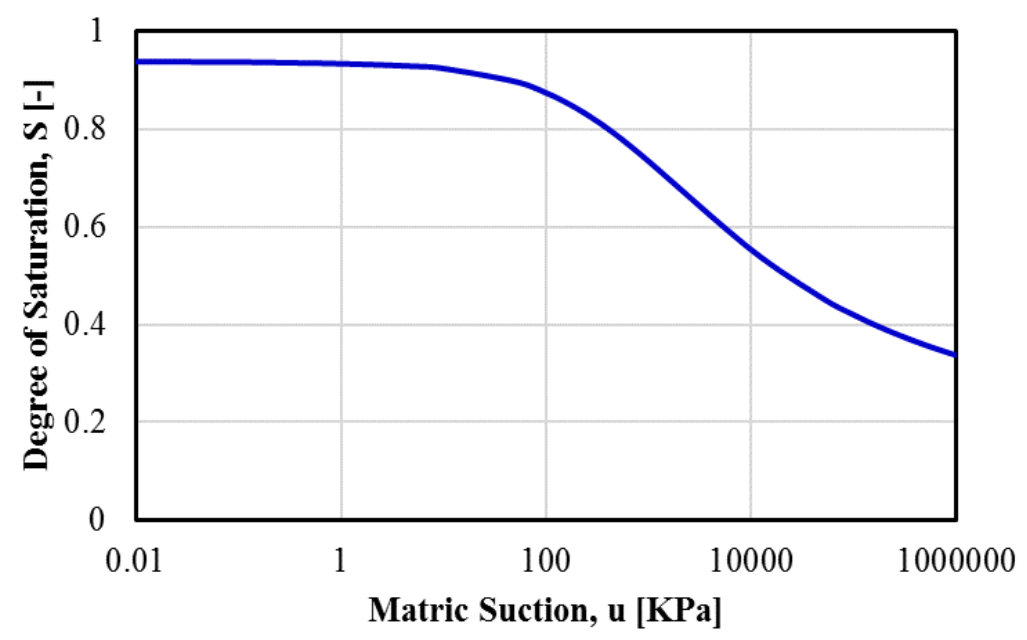

Figure 3Degree of saturation-matric suction relationship for Regina clay 


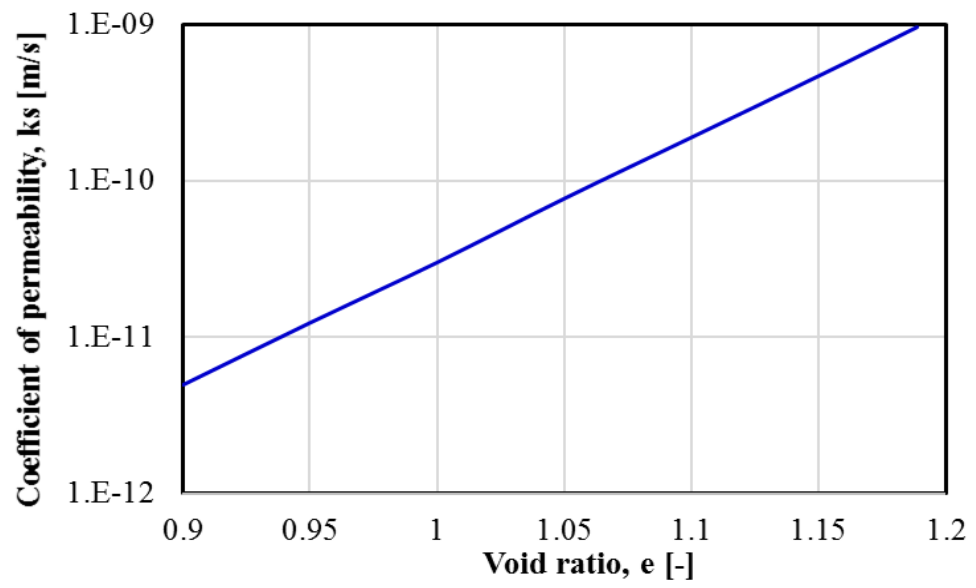

Figure 4Saturated coefficient of permeability as a function of the void ratio for Regina clay [1]

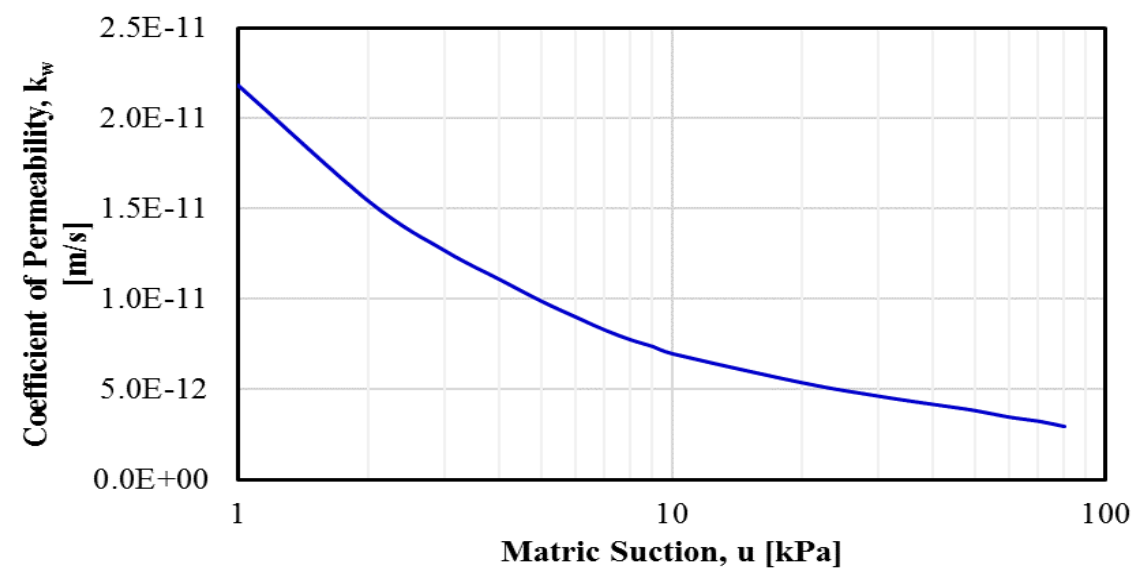

Figure 5The permeability function for Regina clay as a function of the matric suction [1]

The volumetric strain $\left(\varepsilon_{\mathrm{v}}\right)$ was calculated from the change in void ratio (de) as follows

$\varepsilon_{\mathrm{v}}=\frac{\mathrm{de}}{1+\mathrm{e}_{\mathrm{o}}}$

where $e_{o}$ is the initial void ratio of the soil. Figure 6represents the relationship between the volumetric strain and the matric suction for Regina clay.

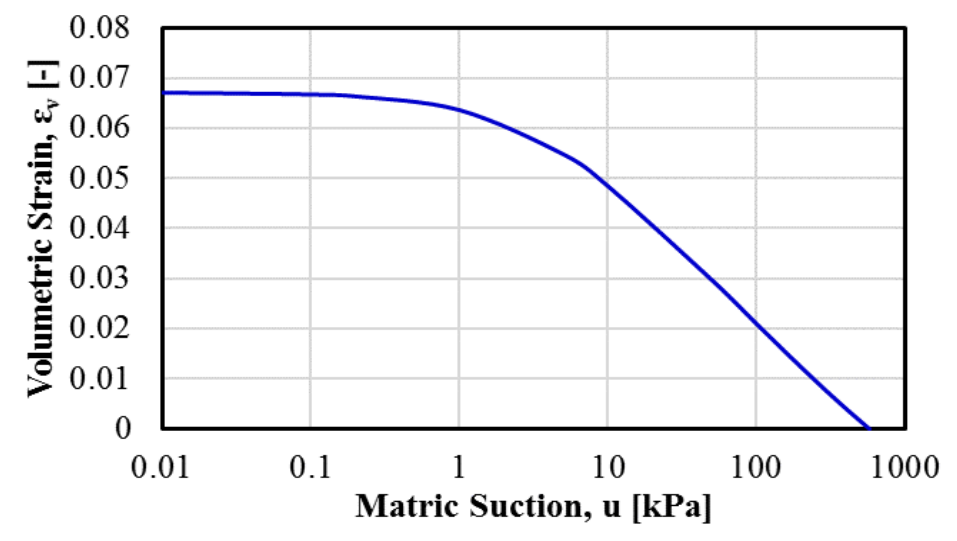

Figure 6Volumetric strain-Matric suction relationship for Regina clay. 


\section{DESCRIPTION OF FINITE ELEMENT MODELS}

\subsection{Finite element model of oedometer}

The implemented numerical model represents a soil specimen with a height of $16 \mathrm{~mm}$ and a diameter of $63 \mathrm{~mm}$. Accordingly, CAX8RP axi-symmetry-reduced integration-pore pressure element was used in this analysis. Figure 7 shows the geometry of the model used in the present work. The two vertical boundaries of the model were restrained from moving in the horizontal direction and set free to move vertically. The top side of the model was allowed to move in the vertical direction. Meanwhile, all horizontal and vertical displacements were constrained at the modelbottom.

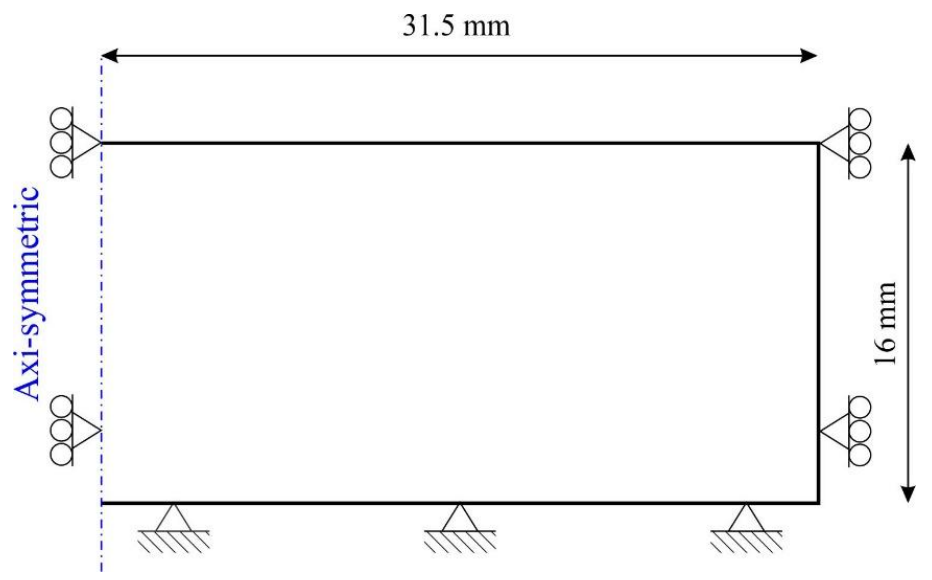

Figure 7 Geometry of the model

The initial condition for saturation was considered as 0.77 throughout the present model. The initial pore pressure was $575 \mathrm{KPa}$ while the initial void ratio was 0.975 . The initial conditions for the effective stress were calculated from the densities of the dry material and the fluid, the initial saturation, the void ratio, and the initial pore pressures using the equilibrium considerations and the effective stress principle. The analysis was performed with a transient soils consolidation procedure using automatic time incrementation [17]. The simulation was performed in several modes and steps. The initial step was performed in order to define the initial void ratio, initial pore pressure, initial saturation, and initial effective stresses throughout the model. The second step was a geostatic step. This step was performed in order to establish the initial equilibrium state. The weight of the soil was applied in this step by a gravity loading (gravitational acceleration equal to $-10 \mathrm{~m} / \mathrm{sec}^{2}$ ). In the third step, the top surface of the model was loaded by applying a small pressure equal to $1 \mathrm{kN} / \mathrm{m}^{2}$. In the fourth step, the top surface of the model was loaded by applying a pressure equal to $45 \mathrm{kN} / \mathrm{m}^{2}$. Then in the next step, the specimen was saturated with water by setting a zero pore pressure at all pore pressure nodes of the model. The vertical heave was recorded and the swelling percentage was calculated. The previous steps were repeated under different pressures. Then a relationship between the swelling percentage and the pressure was drawn. The pressure corresponding to a zero swelling percentage is defined as the swelling pressure [18].

\section{2. model validation}

The experimental results of Shuai [1] were used in order to validate the present numerical model of the Regina clay. Shuai [1] performed a series of oedometer tests on seven specimens to study the volume change of Regina clay and to obtain the swelling pressure for this soil. Each specimen was loaded with different applied loads and consolidated, then the specimen was immersed in water and allowed to swell under the initial applied load. Shuai [1] performed several types of laboratory tests (falling head permeability test, pressure plate test, oedometer tests and shrinkage test) to identify the soil properties. The amount of swell for the oedometer tests was measured. 
The oedometer test of Shuai [1] was simulated using the ABAQUS software in the present work. One CAX8RP axi-symmetry-reduced integration-pore pressure element was used in this analysis. The steps for this simulation were conducted according to the procedure previously described in section (3.1.).Figure 8presents a comparison between the experimental results of Shuai [1] and the present numerical results of the oedometer test. It shows a linear relationship between the swelling percentage and the logarithm of the pressure. The numerical results are in good agreement with the experimental results of Shuai [1]. The swelling pressure was obtained from the results and it was found to be about $337 \mathrm{kPa}$.

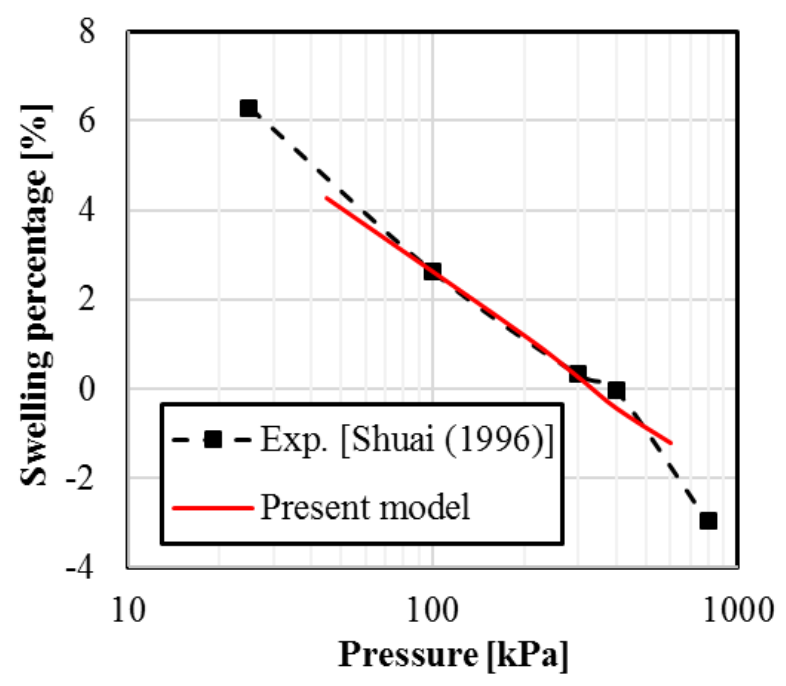

\subsection{Case Study}

Figure 8Volume change behavior of compacted Regina clay

A case study was also simulated in order to verify the present numerical model. In this case study, a slab-on-ground placed on Regina expansive clay and subjected to a constant infiltration rate was considered. This casestudy was modeled byHung [16], considering $5 \mathrm{~m}$ thick deposit of Regina expansive clay that was partially covered with a slab. An infiltration of $2 \times 10^{-8} \mathrm{~m} / \mathrm{s}$ was imposed at the uncovered portion of the ground surface over a period of 175 days as shown in Figure 9.These conditions cause the suctions to increase and the soil to swell.

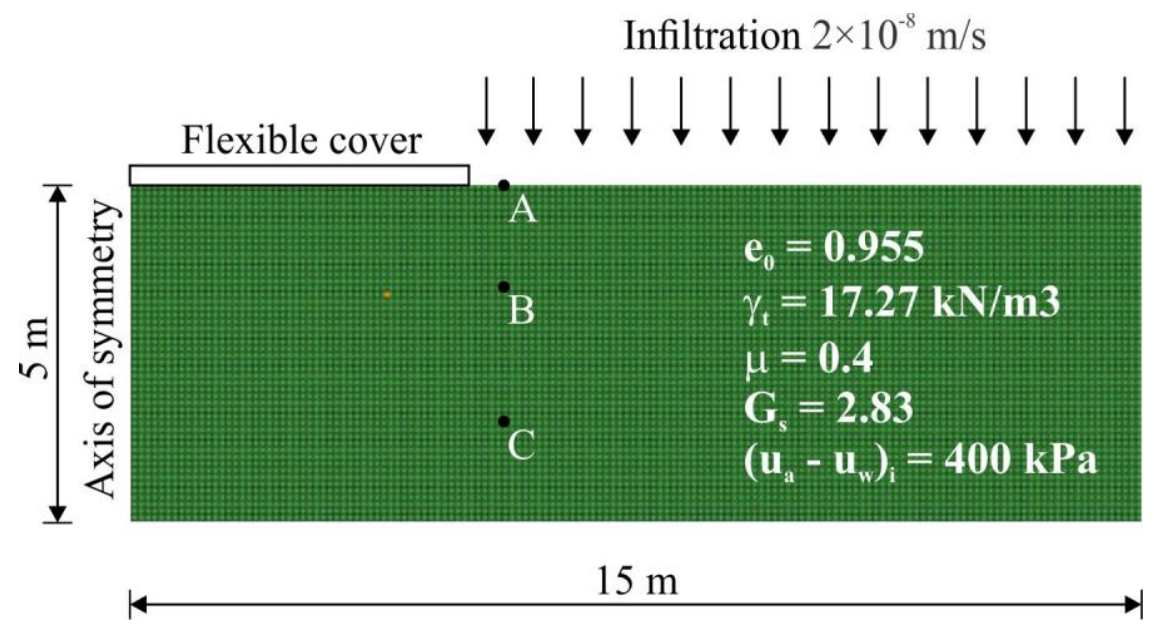

Figure 9Geometry of the case study[16] 
The case study of Hung [16] was re-analyzed using ABAQUS software. Figure 9 shows the finite element mesh used in this case study. The problem was modeled with a uniform 10×10 mesh of CPE8RP plane strain elements. The model is free to move in the vertical direction and fixed in the horizontal direction at the left and right sides of the domain. The lower boundary is fixed in both directions. The initial void ratio was considered as 0.955 throughout the model. The initial saturation is 0.7824 . The initial pore pressure is $-400000 \mathrm{~Pa}$. The initial conditions for effective stress are calculated from the density of the dry material and fluid, the initial saturation, and void ratio, and the initial pore pressures and they are $313 \mathrm{kPa}$ at the top of the model and $403 \mathrm{kPa}$ at the model bottom. The soil weight was applied by a gravity loading and the analysis was performed in two steps. The first step is an initial step of a geostatic analysis which was performed to establish the initial equilibrium state. The initial conditions in the model exactly balance the weight of the fluid and the dry material so that no deformation takes place. Then, the fluid was allowed to enter through the top of the model by applying a surface pore fluid load. The transient analysis was performed using automatic time incrementation.

Figure 10presents a comparison between the results of Hung [16]and the present model for the vertical displacement at points A, B and C. The heave at point A is higher than that of points B and C. A good agreement between the present results and that of Hung [16]was obtained at the three points. Thereby, the present numerical model was validated.

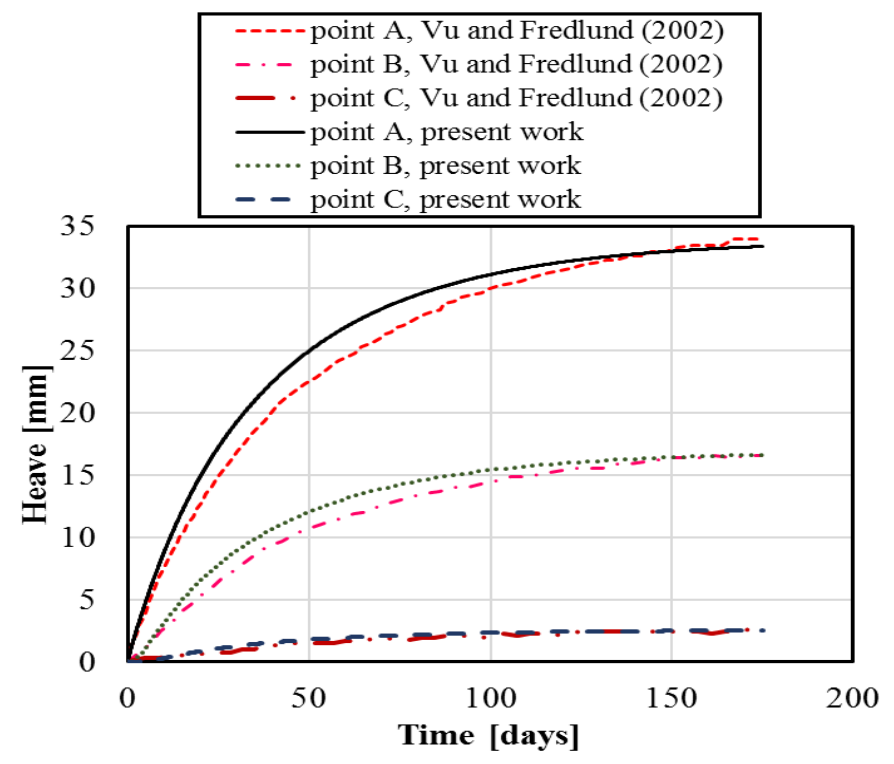

Figure 10Comparison between the present results and the results of Hung (2002)[16]

\section{PARAMETRIC ANALYSIS OF SWCC BEHAVIOR}

\subsection{Effect of the fitting parameter "a" on swelling pressure}

Different SWCCs were established by varying the fitting parameter "a" in Equation (1) while keeping the other fitting parameters at their original values. Figure 11shows the SWCC for different values of the fitting parameter "a". The value of "a" was gradually varied from $1 \mathrm{kPa}$ to $600 \mathrm{kPa}$ and the model was simulated under these different values. Increasing the value of "a" significantly increases the soil air entry value. Figure 12 introduces the effect of the initial matric suction on the swelling pressure for different values of the fitting parameter "a". The swelling pressure increases with increasing the initial matric suction. This is because increasing the initial matric suction of the soil increases the soil ability to absorb a greater amount of water and this causes an increase in heave.

The swelling pressure linearly varies with the initial matric suction at different values of "a" (i.e., different air entry values). For an initial matric suction of $100 \mathrm{kPa}$, increasing the value of "a" 
from $1 \mathrm{kPa}$ to $100 \mathrm{kPa}$ decreases the swelling pressure from $96 \mathrm{kPa}$ to $74.3 \mathrm{kPa}(22.6 \%)$ while increasing the value of "a" from $1 \mathrm{kPa}$ to $300 \mathrm{kPa}$ decreases the swelling pressure from $96 \mathrm{kPa}$ to $67.7 \mathrm{kPa}(29.5 \%)$. Meanwhile, increasing the value of "a" from $1 \mathrm{kPa}$ to $600 \mathrm{kPa}$ decreases the swelling pressure from $96 \mathrm{kPa}$ to $64.57 \mathrm{kPa}(32.74 \%)$. For an initial matric suction of $1000 \mathrm{kPa}$, increasing the value of "a" from $1 \mathrm{kPa}$ to $100 \mathrm{kPa}$ decreases the swelling pressure from $697.9 \mathrm{kPa}$ to $665.9 \mathrm{kPa}(4.57 \%)$, increasing the value of "a" from $1 \mathrm{kPa}$ to $300 \mathrm{kPa}$ decreases the swelling pressure from $697.9 \mathrm{kPa}$ to $620.94 \mathrm{kPa}(11 \%)$, and increasing the value of "a" from $1 \mathrm{kPa}$ to 600 $\mathrm{kPa}$ decreases the swelling pressure from $697.9 \mathrm{kPa}$ to $603.47 \mathrm{kPa}(13.5 \%)$. This means that soils with a high value of the fitting parameter "a" will produce less swelling pressure at all values of the initial matric suction.

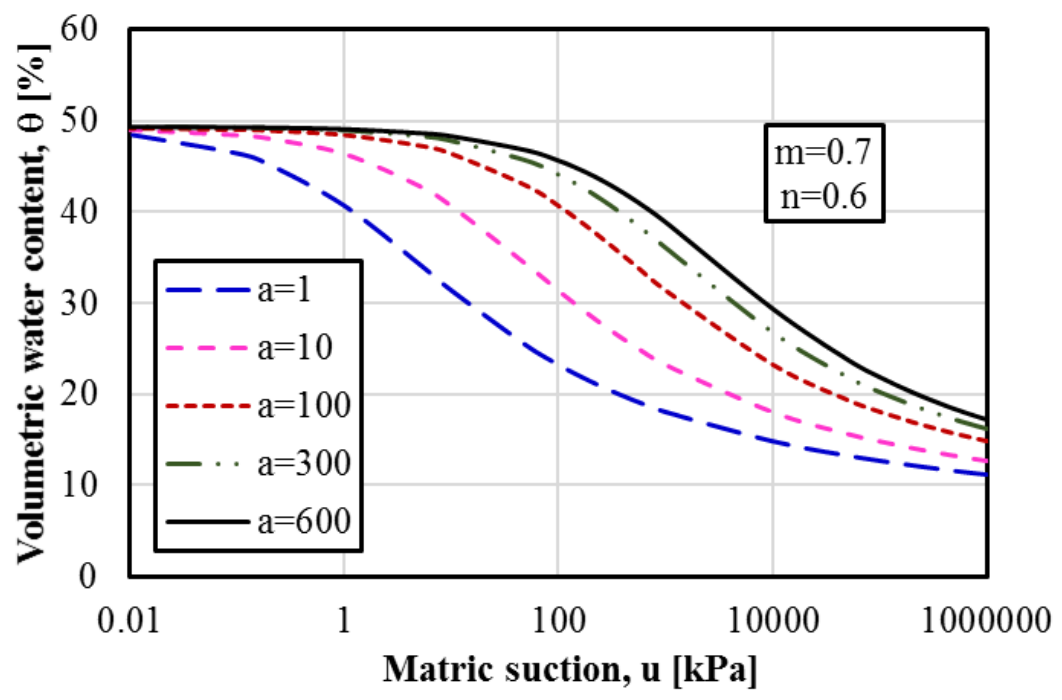

Figure 11 SWCC for different values of the fitting parameter "a"

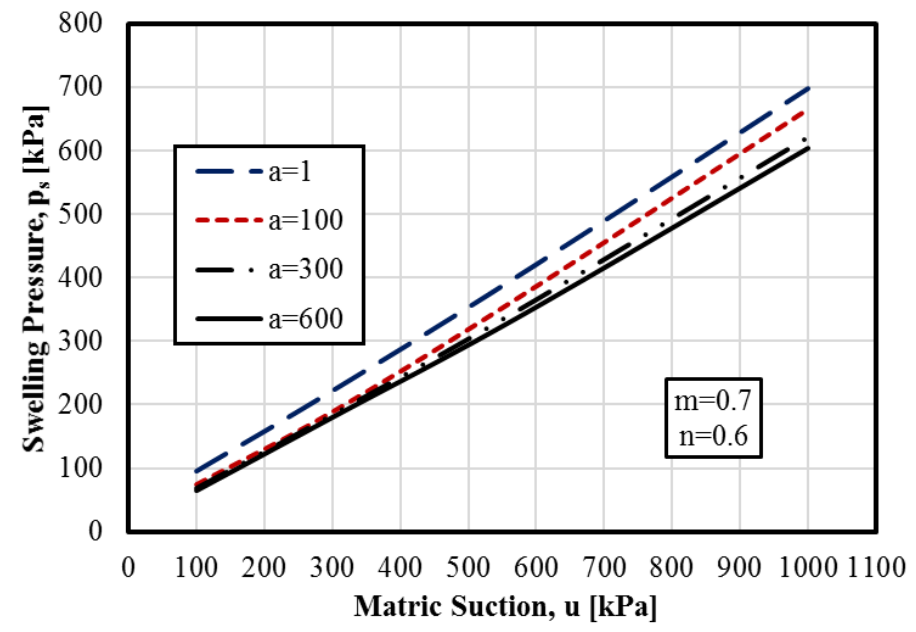

Figure 12Variation of the swelling pressure with the soil suction for different values of "a"

\subsection{Effect of the fitting parameter " $\mathrm{m}$ " on the swelling pressure}

The fitting parameter " $\mathrm{m}$ " represents the slope of the SWCC in the high suction range. Different SWCCs were generated by varying the value of the fitting parameter "m" in Equation (1) while maintaining the original values of the other fitting parameters. Figure 13shows the SWCC for different values of the fitting parameter " $\mathrm{m}$ ". Small values of " $\mathrm{m}$ " result in a moderate slope of the SWCC in the high suction range while large values of " $m$ " result in a sharp slope of the 
SWCC in the same suction range. The expansive soil behavior was simulated using the SWCCs of Figure 13 at different values of the initial matric suction. Figure 14shows the effect of the initial matric suction on the swelling pressure for different values of the fitting parameter " $m$ ". For an initial matric suction of $300 \mathrm{kPa}$, increasing the value of " $\mathrm{m}$ " from 0.35 to 0.7 increases the swelling pressure from $168.3 \mathrm{kPa}$ to $179.3 \mathrm{kPa}(6.5 \%)$ while increasing the value of "m" from 0.35 to $1.4 \mathrm{kPa}$ increases the swelling pressure from $168.3 \mathrm{kPa}$ to $205.7 \mathrm{kPa}(22.2 \%)$. For an initial matric suction of $1000 \mathrm{kPa}$, increasing the value of " $\mathrm{m}$ " from 0.35 to 0.7 increases the swelling pressure from $556.5 \mathrm{kPa}$ to $653.33 \mathrm{kPa}(17.4 \%)$ while increasing the value of " $\mathrm{m}$ " from 0.35 to $1.4 \mathrm{kPa}$ increases the swelling pressure from $556.5 \mathrm{kPa}$ to $811.48 \mathrm{kPa}(45.8 \%)$. This means that the slope of the SWCC significantly affects the expansive soil characteristics at all investigated values of the initial matric suction. Soils with high values of the fitting parameter "m" will produce higher swelling pressure at all values of the initial matric suction.

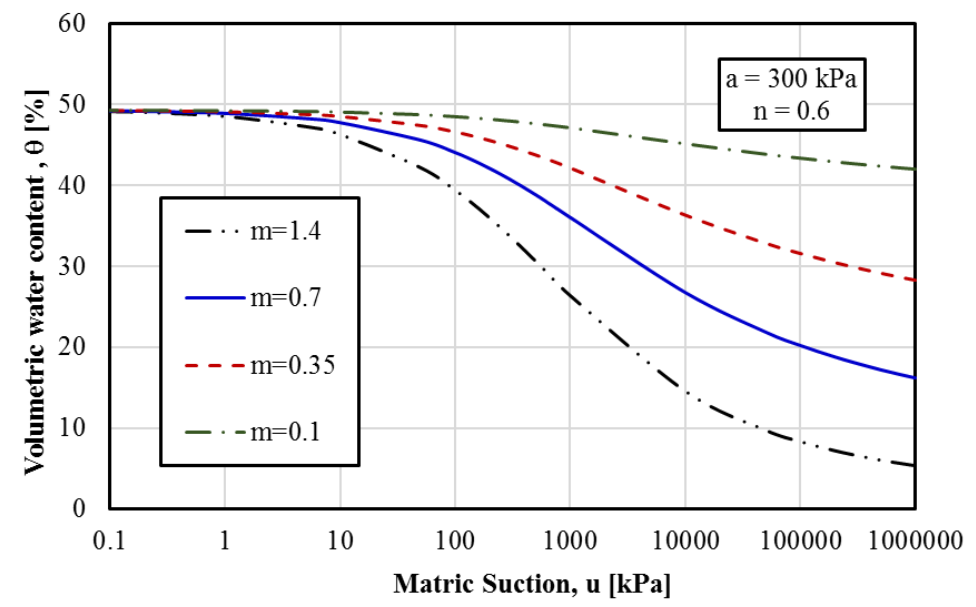

Figure 13 SWCC for different values of the fitting parameter " $m$ "

\subsection{Effect of the fitting parameter " $n$ " on the swelling pressure}

The fitting parameter " $n$ " represents the rate of desaturation at the inflection point in the soilwater characteristic curve. The effect of the fitting parameter " $n$ " on the swelling pressure was investigated by generating SWCCs with different values of " $\mathrm{n}$ " as shown in Figure 15. Small values of " $n$ " result in a moderate slope of the SWCC near the air-entry value while large values of " $n$ " result in a sharp slope of SWCC near the air-entry value. The soil behavior was simulated using these curves. Figure 16 presents the effect of the initial matric suction on the swelling pressure for different values of the fitting parameter " $n$ ". For an initial matric suction of $300 \mathrm{kPa}$, increasing the value of " $\mathrm{n}$ " from 0.15 to 0.3 increases the swelling pressure from $146.7 \mathrm{kPa}$ to $160.7 \mathrm{kPa}(9.5 \%)$ while increasing " $\mathrm{n}$ " from 0.15 to $0.6 \mathrm{kPa}$ increases the swelling pressure from $146.7 \mathrm{kPa}$ to $179.3 \mathrm{kPa}(22.2 \%)$. For an initial matric suction of $1000 \mathrm{kPa}$, increasing the value of " $\mathrm{n}$ " from 0.15 to 0.3 increases the swelling pressure from $470.9 \mathrm{kPa}$ to $523.8 \mathrm{kPa}(22.2 \%)$ while increasing the value of " $\mathrm{n}$ " from 0.15 to $0.6 \mathrm{kPa}$ increases the swelling pressure from $470.9 \mathrm{kPa}$ to $619.1 \mathrm{kPa}(31.5 \%)$. This shows a significant effect of " $n$ " for all investigated values of the initial matric suction. Soils with a high value of the fitting parameter "n" will produce higher swelling pressure. At the same initial matric suction, soils with a higher value of the fitting parameter " $n$ " (higher rate of desaturation) will have a lower initial water content and this will produce a higher swelling pressure. 


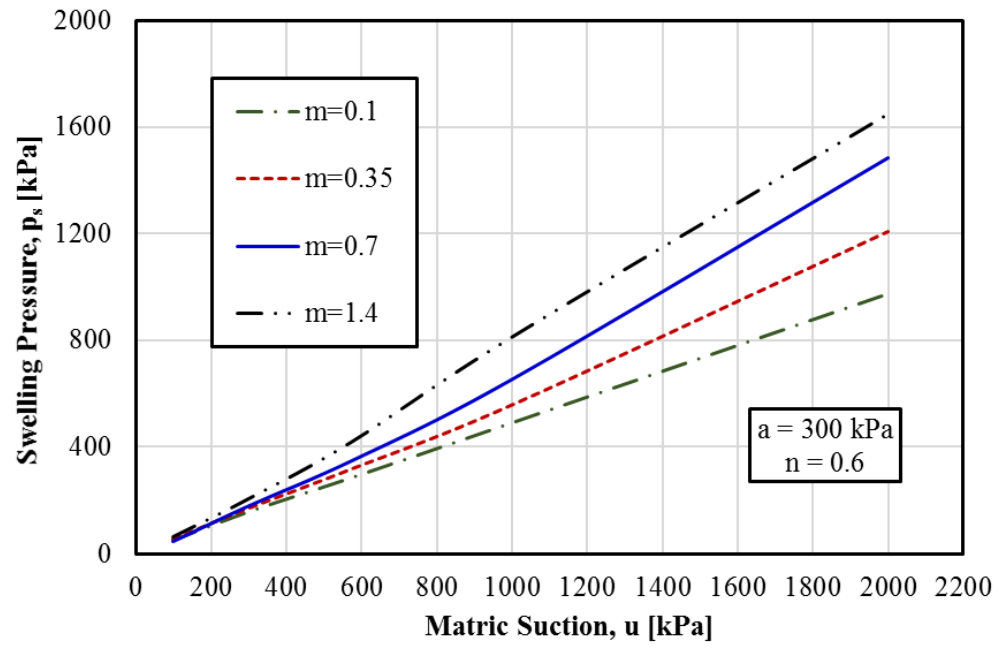

Figure 14Variation of the swelling pressure with the soil suction for different values of " $\mathrm{m}$ "

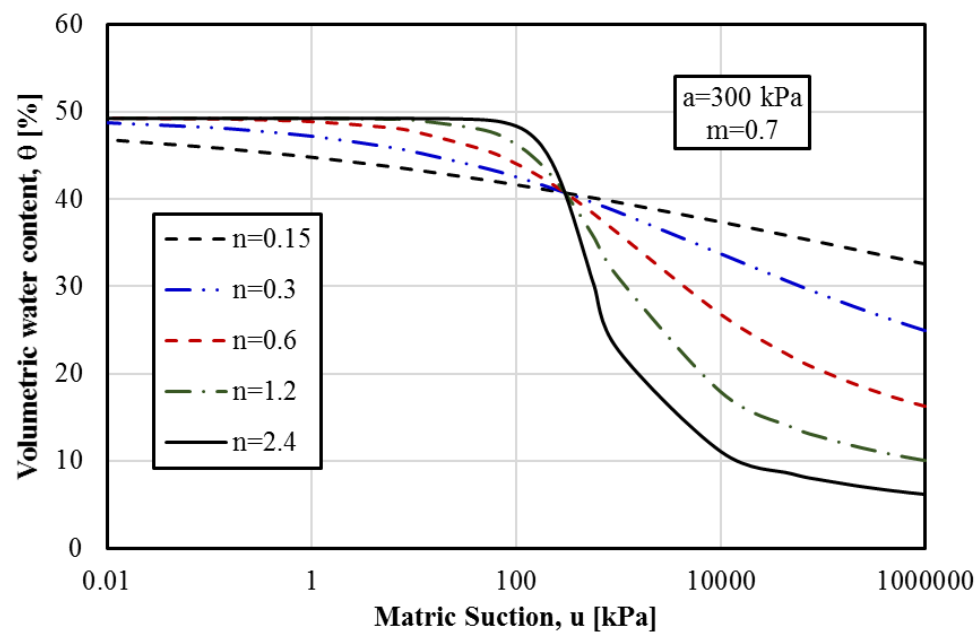

Figure 15SWCC for different values of the fitting parameter "n"

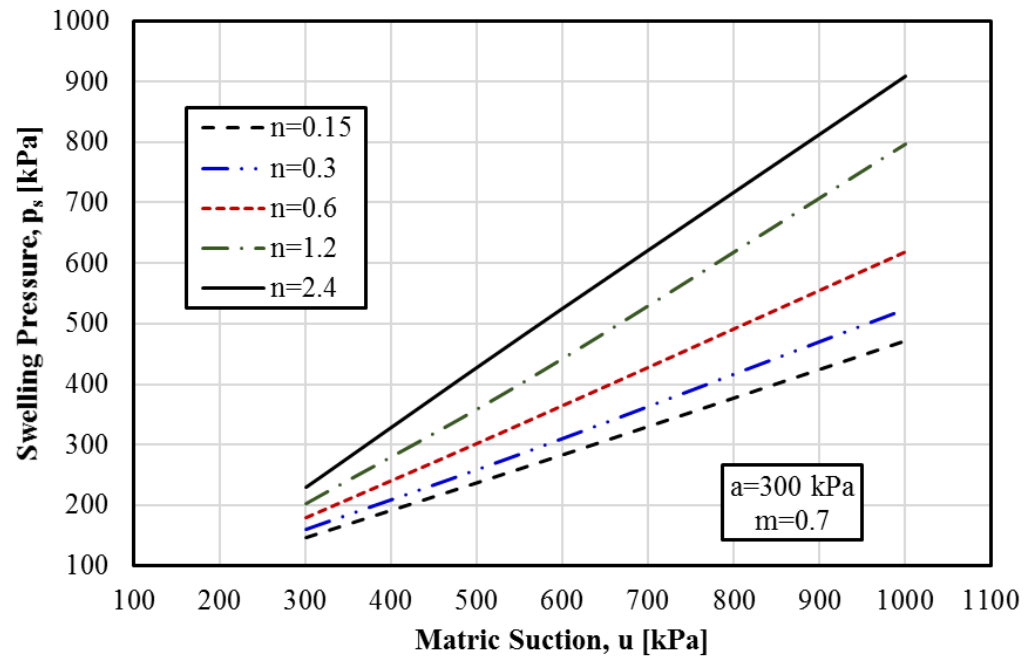

Figure 16Variation of the swelling pressure with the soil suction for different values of " $n$ " 


\section{CONCLUSIONS}

The present work investigates the interplay of the Soil Water Characteristics Curve (SWCC) with the swelling pressure of expansive soils. Numerical simulation using the ABAQUS software was conducted for the oedometer test of the expansive Regina clay. The SWCC of the Regina expansive soil was represented using three fitting parameters (a, $\mathrm{m}$, and $\mathrm{n}$ ) according to Fredlund and Xing (1994) equation. The effect of the fitting parameters on the swelling pressure of expansive soils was thoroughly investigated. The following conclusions can be drawn from the present study:

i. Swelling pressure linearly increases with increasing the initial soil suction.

ii. Expansive soils with a high value of the fitting parameter " $a$ " have low swelling pressure. At the same matric suction, increasing the value of "a" indicates a higher soil air entry value. In this case, the soil will have a higher initial water content and this will produce a lower swelling pressure.

iii. The effect of the fitting parameter "a" on the expansive soil behavior is more tangible at low values of the matric suction.

iv. Soils having high values of the fitting parameter " $\mathrm{m}$ " produces high swelling pressure. At the same matric suction, increasing the value of "m" indicates a higher slope of the SWCC in the high suction range. In this condition, the soil will have a lower initial water content and this will produce a higher swelling pressure.

$v$. Expansive soils with high values of the fitting parameter " $n$ " introduce higher swelling pressure. At the same matric suction, increasing the value of " $n$ " means a higher rate of desaturation(slope of SWCC near the air entry value). In this case, the soil will have a lower initial water content and this will produce a higher swelling pressure.

In summary, a SWCC of an expansive soil with fitting parameters a $>300 \mathrm{kPa}, \mathrm{m}<0.7$, and $\mathrm{n}<0.6$ will have a swelling pressure lower than that of the Regina clay (about $337 \mathrm{kPa}$ ) and vice versa.

\section{REFERENCES}

1. Shuai F. (1996). "Simulation of swelling pressure measurements on expansive soils". Ph.D. thesis, University of Saskatchewan, Canada.

2. Maio, C. (2001). "Swelling pressure of clayey soils: the influence of stress state and poreliquid composition". Rivista Italiana di Geotecnica, pp. 22-34.

3. Tu H. and Vanapalli S.K. (2015). "Prediction of the variation of swelling pressure and 1-D heave of expansive soils with respect to suction using the soil water retention curve as a tool". Canadian Geotechnical Journal cgj-2015-0222.R1, University of Ottawa, Canada.

4. Fredlund, D.G. and Xing, A. (1994)."Equations for the soil-water characteristic curve", Canadian Geotechnical Journal, 31(3): 521-532, 1994, Saskatoon, Canada.

5. Alim, Md., Nishigaki, M., Chegbeleh, L., Akudago, J. and Komatsu, M. (2009). "Determination of Soil Water Characteristic Curves of unsaturated sandy soils using membrane filter with stainless wire mesh",Journal of the Faculty of Environmental Science and Technology, Okayama University, Vol. 14 No 1, pp. 13-16.

6. Morsi Y. (2010) "Numerical modelling of expansive soils using uncoupled approach" Ph.D. thesis. Cairo University.

7. Zhang X., (2004) "Consolidation theories for saturated-unsaturated soils and numerical simulation of residential buildings on expansive soils" Ph.D. Thesis. Texas A\&M University, College Station, TX.

8. Börgesson, L. 2004. Modelling of FEBEX in-situ test-Coupled thermo-hydro-mechanical analysis of the buffer and the rock. International Progress Report IPR-08-12. 
9. Vu, H.Q. and Fredlund, D.G. 2006. Challenges to modelling heave in expansive soils. Canadian Geotechnical Journal, 43(12): 1249-1272.

10. Zhou Yiyi. Numerical and experimental studies of influence of trees on ground movements in expansive soils. PhD Thesis, RMIT University 2011.

11. Hung, Q., Fredlund, D. G. and J. H. F. Pereira (2001). "Analysis of swelling behavior of soils by a coupled solution", International Conference on Management of the Land and Water Resources, MLWR, Hanoi, Vietnam.

12. Fredlund D.G., Rahardjo H. and Fredlund M.D. 2012 "Unsaturated soil mechanics in engineering practice"

13. Hsuan, H., Chung-Ching, H. (2013) "Numerical modelling for undrained shear strength of clays subjected to different plasticity indexes", Journal of Geo-Engineering, Vol. 8, No. 3, pp.91-100.

14. Shunchao Qi, Sai K. Vanapalli (2015). "Influence of swelling behavior on the stability of an infinite unsaturated expansive soil slope". Computers and Geotechnics 76(2016)54-169.

15. Hung, Q. and Fredlund, D. G. (2004). "Prediction of one-, two-, and three-dimensional heave in expansive soils". Canadian Geotechnical JournalVol. (41), pp.713-737.

16. $\mathrm{Vu}, \mathrm{H} . \mathrm{Q}$. 2003. Uncoupled and coupled solutions of volumechange problems in expansive soils. Ph.D. thesis, Department ofCivil Engineering, University of Saskatchewan, Saskatoon, Sask.

17. ABAQUS/CAE user manual (2014). Version 6.14, United State of America.

18. Egyptian code of soil mechanics and design and implementation of foundations. Part two. Laboratory tests (2001). 